\title{
A Secreted 'Candidatus Liberibacter asiaticus' Peroxiredoxin Simultaneously Suppresses Both Localized and Systemic Innate Immune Responses In Planta
}

\author{
Mukesh Jain, Alejandra Munoz-Bodnar, Shujian Zhang, and Dean W. Gabriel ${ }^{\dagger}$ \\ Department of Plant Pathology, University of Florida, Gainesville, FL 32611, U.S.A. \\ Accepted 26 June 2018.
}

\begin{abstract}
The oxidative $\left(\mathrm{H}_{2} \mathrm{O}_{2}\right)$ burst is a seminal feature of the basal plant defense response to attempted pathogen invasions. In 'Candidatus Liberibacter asiaticus' UF506, expression of the SC2 prophage-encoded secreted peroxidase (F489_gp15) increases bacterial fitness and delays symptom progression in citrus. Two chromosomal 1-Cys peroxiredoxin genes, CLIBASIA_RS00940 (Lasprx5) and CLIBASIA_RS00445 (Lasbcp), are conserved among all sequenced ' $\mathrm{Ca}$. L. asiaticus' strains, including those lacking prophages. Both LasBCP and LasdPrx5 have only a single conserved peroxidatic $\mathrm{Cys}\left(\mathrm{C}_{\mathrm{P}} / \mathrm{SH}\right)$ and lack the resolving $\mathrm{Cys}\left(\mathrm{C}_{\mathrm{R}} / \mathrm{SH}\right)$. Lasprx5 appeared to be a housekeeping gene with similar moderate transcript abundance in both ' $\mathrm{Ca}$. L. asiaticus'-infected psyllids and citrus. By contrast, Lasbcp was expressed only in planta, similar to the expression of the SC2 peroxidase. Since ' $C a$. L. asiaticus' is uncultured, Lasbcp and Lasprx 5 were functionally validated in a cultured surrogate species, Liberibacter crescens, and both genes significantly increased oxidative stress tolerance and cell viability in culture. LasBCP was nonclassically secreted and, in $L$. crescens, conferred 214-fold more resistance to tert-butyl hydroperoxide $(t \mathrm{BOOH})$ than wild type. Transient overexpression of Lasbcp in tobacco suppressed $\mathrm{H}_{2} \mathrm{O}_{2}$-mediated transcriptional activation of $R b o h B$, the key gatekeeper of the systemic plant defense signaling cascade. Lasbcp expression did not interfere with the perception of ' $\mathrm{Ca}$. L. asiaticus' flagellin $\left(\mathbf{f l g 2 2 _ { \text { Las } } )}\right.$ but interrupted the downstream activation of $R b o h B$ and stereotypical deposition of callose in tobacco. Critically, LasBCP also protected against $t \mathrm{BOOH}$-induced peroxidative degradation of lipid membranes in planta, preventing subsequent accumulation of antimicrobial oxylipins that can also trigger the localized hypersensitive cell death response.
\end{abstract}

Current address for Shujian Zhang: New Mexico Consortium Biolab, Los Alamos, NM 87544, U.S.A.

${ }^{\dagger}$ Corresponding author: Dean W. Gabriel; E-mail: dgabr@ufl.edu

Funding: This work was supported by the Florida Citrus Research and Development Foundation (CRDF) project number 15-009 and the United States Department of Agriculture National Institute of Food and Agriculture Specialty Crops Research Initiative grant number 2016-70016-24844.

*The $\boldsymbol{e}$-Xtra logo stands for "electronic extra" and indicates that two supplementary figures are published online.

() 2018 The American Phytopathological Society
Huanglongbing (HLB), or citrus greening, has emerged as the single most devastating citrus disease worldwide. HLB is associated with three fastidious and uncultured $\alpha$-proteobacteria; 'Candidatus Liberibacter asiaticus' in Asia and the Americas, ' $\mathrm{Ca}$. Liberibacter americanus' in Brazil, and ' $\mathrm{Ca}$. Liberibacter africanus' in Africa. ' $\mathrm{Ca}$. L. asiaticus' is vectored and transmitted among citrus and some Rutaceae species by the Asian citrus psyllid Diaphorina citri Kuwayama (Sternorrhyncha: Psyllidae) (Grafton-Cardwell et al. 2013). In psyllids, ' $C a$. L. asiaticus' propagates both inter- and intracellularly as a systemic, circulative, and propagative endosymbiont across multiple organs. 'Ca. L. asiaticus' infection in psyllids doesn't cause any overt disease symptoms, except for localized apoptosis in the midgut epithelium cells of the adult insects (Ghanim et al. 2017) but not in the nymphs (Mann et al. 2018).

By contrast, ' $\mathrm{Ca}$. L. asiaticus' colonization of citrus phloem significantly compromises its transport functions. Altered nutrient and assimilate partitioning in citrus reduces fruit yield and quality and causes progressive decline and death of infected trees. Despite the complete genome sequencing of at least nine ' $C a$. L. asiaticus' strains (Duan et al. 2009; Katoh et al. 2014; Wu et al. 2015; Zheng et al. 2015), genetic determinants of ' $C a$. L. asiaticus' pathogenicity and host range in plants and its ability to systemically colonize insect hosts remain largely unknown. To date, all efforts to obtain sustained growth of ' $C a$. L. asiaticus' in axenic cultures have failed, thus restricting functional genomics studies and subsequent development of effective chemical control methods (Jain et al. 2015; Pitino et al. 2016; Zou et al. 2012).

Recognition of conserved pathogen-associated molecular patterns (PAMPs) and damage-associated molecular patterns (DAMPs) by integral pathogen recognition receptors results in activation of pattern-triggered immunity or basal resistance in plants (Boutrot and Zipfel 2017; Choi and Klessig 2016). Compatible host-pathogen interactions are marked by low-amplitude, nonspecific apoplastic bursts of reactive oxygen species (ROS) (primarily $\mathrm{H}_{2} \mathrm{O}_{2}$ ) in response to PAMPs or DAMPs that are mediated through the action of respiratory burst oxidase homologs (RBOHs) (Baxter et al. 2014; Kadota et al. 2015). However, a second high-amplitude oxidative burst occurs during incompatible host-pathogen interactions, resulting in the establishment of effective disease resistance (Grant and Loake 2000). Successful infections by biotrophic plant pathogens are contingent upon detoxification of the first wave of ROS and active suppression of basal plant defenses (Kadota et al. 2015).

ROS (e.g., $\mathrm{O}_{2}^{\bullet-}, \mathrm{H}_{2} \mathrm{O}_{2}, \mathrm{OH}^{\bullet},{ }^{1} \mathrm{O}_{2}$ ) are byproducts of cellular metabolism, also serving as long distance signal transducers 
within defense and developmental networks (Miller et al. 2009). ROS target polyunsaturated lipids, Cys residues, Fe-S clusters, and DNA (Imlay 2014). Nonenzymatic ROS-induced lipid peroxidation also results in accumulation of highly reactive $\alpha, \beta$-unsaturated carbonyl compounds (reactive electrophilic species), primarily oxylipins. Oxylipins are various oxygenated derivatives of polyunsaturated fatty acids such as linoleic acid (18:2) and $\alpha$-linolenic acid (18:3) and have well-known signaling functions in animals and in plants (Farmer and Mueller 2013). Oxylipins contribute to plant defense by overlapping effects on pathogens by direct antimicrobial activity, transcriptional activation of defense genes, and regulation of cell death (Prost et al. 2005).

Spatiotemporal regulation of ROS generation and detoxification pathways is critical for maintaining redox poise while preventing oxidation of cellular macromolecules (Schieber and Chandel 2014). The SC2 peroxidase (F489_gp15) in ' $\mathrm{Ca}$. L. asiaticus' UF506 (Zhang et al. 2011) was functionally characterized as a secreted effector and was demonstrated to suppress $\mathrm{H}_{2} \mathrm{O}_{2}$-mediated transcriptional activation of Rbohb in planta, a prerequisite for innate plant immune defense or basal resistance (Jain et al. 2015). However, absence of the peroxidase in some 'Ca. L. asiaticus' strains lacking prophages, such as YCpsy (Wu et al. 2015), FL17 (Zheng et al. 2015), and Ishi-1 (Katoh et al. 2014), indicated the presence of an alternative ROS detoxification enzyme for these strains to survive in citrus.

Two chromosomal peroxiredoxin genes CLIBASIA_RS00940 (Lasprx5) and CLIBASIA_RS00445 (Lasbcp) are identically conserved among all nine ' $C a$. L. asiaticus' strains sequenced to date, including the phage-less strains. CLIBASIA_RS00445 protein was recently purified to homogeneity and characterized to have a protective role against peroxide-mediated cell death and oxidative damage in vitro (Singh et al. 2017). Peroxiredoxin proteins (EC 1.11.1.15) are a diverse family of ubiquitous thioredoxin-scaffold enzymes with Cys-dependent and promiscuous peroxidase activity on hydrogen peroxide, peroxynitrite, and organic peroxide substrates. The specificities for the thiol-containing donor substrate vary considerably, comprising glutathione, trypanothione, thioredoxin, and tryparedoxin (Hofmann et al. 2002). Peroxiredoxins utilize either 2Cys or 1-Cys reaction catalysis mechanisms, the latter of which is redox insensitive (Nelson et al. 2011). The broad distribution and high expression levels across all cell types is indicative of peroxiredoxins being an ancient and important enzyme family. Escherichia coli peroxiredoxin is one among the ten most abundant cellular proteins and the primary enzyme responsible for the reduction of endogenously generated $\mathrm{H}_{2} \mathrm{O}_{2}$ (Seaver and Imlay 2001).

The primary objective of this research was to identify critical virulence effectors of ' $\mathrm{Ca}$. L. asiaticus' in citrus hosts. The strikingly lengthy incubation period between the time of initial infection and the first appearance of HLB symptoms was inexplicable without a mechanism of ' $\mathrm{Ca}$. L. asiaticus'mediated ROS suppression. The discovery of ' $\mathrm{Ca}$. L. asiaticus' strains lacking prophage-encoded peroxidases drew attention to the highly conserved chromosomal 1-Cys peroxiredoxins found in all pathogenic Liberibacter species, and prompted i) examination of the differences (if any) in the transcriptional profiles of putative ' $\mathrm{Ca}$. L. asiaticus' peroxiredoxin genes Lasprx 5 and Lasbcp in psyllid and citrus hosts, ii) attempts to functionally validate LasPrx 5 and LasBCP as peroxiredoxins, using Liberibacter crescens (Leonard et al. 2012), a culturable and genetically tenable surrogate species for uncultured Liberibacter species (Fleites et al. 2014; Jain et al. 2015), and iii) to determine a role, if any, for the (predicted) secreted LasBCP in dampening the $\mathrm{H}_{2} \mathrm{O}_{2}$-mediated defense responses in planta.

\section{RESULTS}

Two chromosomally encoded peroxiredoxin genes in ' $\mathrm{Ca}$. L. asiaticus' are conserved among all Liberibacter species.

Two putative peroxiredoxin genes, CLIBASIA_RS00940 (Lasprx5) and CLIBASIA_RS00445 (Lasbcp), are annotated in ' $C a$. L. asiaticus' psy62 (Duan et al. 2009) and are $100 \%$ conserved among all ' $C a$. L. asiaticus' strains sequenced to date. Lasprx 5 and Lasbcp showed 73 to $82 \%$ and 75 to $80 \%$ protein sequence identity, respectively, to peroxiredoxins annotated in other pathogenic $\mathrm{Ca}$. Liberibacter species and several other $\alpha$-proteobacteria, but only 65 and $60 \%$ sequence identity with L. crescens (Supplementary Figs. S1 and S2). LasPrx 5 encodes a PRX5-like peroxiredoxin, whereas Lasbcp encodes a bacterioferritin comigratory protein (BCP)-like peroxiredoxin. LasPrx5 and LasBCP each have a single peroxidatic Cys ( $\mathrm{C}_{\mathrm{P}} 55 / \mathrm{SH}$ and $\mathrm{C}_{\mathrm{P}} 46 / \mathrm{SH}$, respectively) contained within an absolutely conserved $\mathrm{PXXX}(\mathrm{T} / \mathrm{S}) \mathrm{XXC} \mathrm{C}_{\mathrm{P}}$ motif typical of Cysbased nonheme peroxidases. Both proteins lack the resolving cysteine $\left(\mathrm{C}_{\mathrm{R}} / \mathrm{SH}\right)$ residue. LasPrx 5 and LasBCP display the wellconserved catalytic triad (T52/C55/R132 and T43/C46/R121, respectively), that utilizes the H-bond within the Thr hydroxyl group and the positive charge of the Arg sidechain for deprotonation of the catalytic Cys thiol (Wood et al. 2003). Additionally, a dimerization interface, characteristic of redox-insensitive atypical 2-Cys peroxiredoxins (P53, D85, F87, G107, S108, and R132) (Evrard et al. 2004), is also found within the amino acid sequence of LasPrx5. A similar dimerization interface was absent from LasBCP, characteristic of BCP-like peroxiredoxin subfamily members, the only peroxiredoxin proteins known to function as monomers.

\section{Lasbcp is significantly upregulated in planta relative to the insect host.}

Comparative expression analyses revealed that Lasbcp and Lasprx 5 were differentially expressed in ' $\mathrm{Ca}$. L. asiaticus' infecting its citrus and psyllid hosts (Fig. 1). Similar and moderate transcript abundance was observed for Lasprx 5 in both ' $C a$. L. asiaticus' hosts, in line with the predicted housekeeping functions of PRX5 homologs. However, the expression of Lasbcp was significantly downregulated and

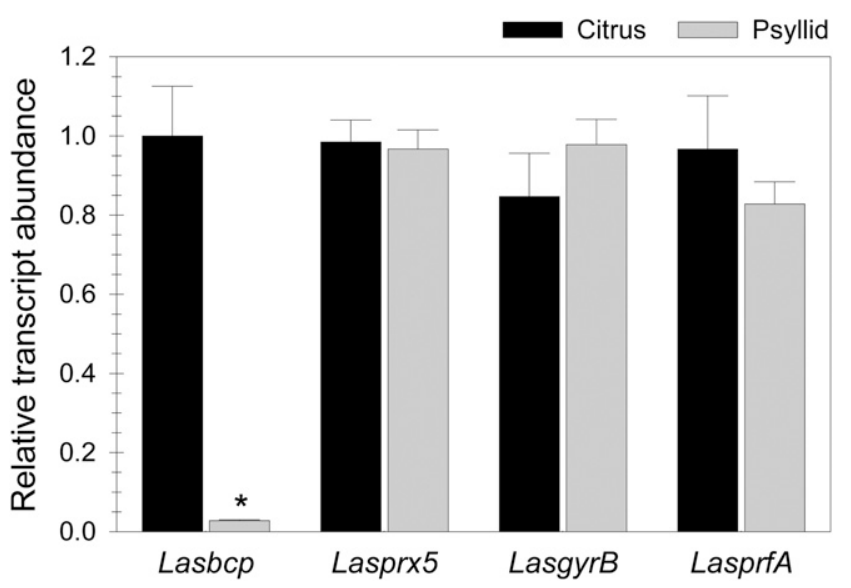

Fig. 1. 'Candidatus Liberibacter asiaticus' peroxiredoxin gene Lasbcp is expressed in citrus but not in psyllids. Relative expression of peroxiredoxin genes Lasbcp and Lasprx 5 and the two endogenous housekeeping genes LasgyrB and LasprfA in citrus and psyllid hosts. Relative transcript abundance of each gene was normalized against its expression in ' $\mathrm{Ca}$. L. asiaticus'-infected citrus. The data presented are the means \pm standard error for three independent experiments with four replicates. An asterisk indicates a significant difference between the means for Lasbcp $(P<0.05)$. 
nearly undetectable in psyllids $(P=0.000096)$, similar to the low level of SC2_gp095 peroxidase expression reported previously in psyllids (Jain et al. 2015). The difference in expression levels of chromosomal genes LasgyrB and LasprfA in both hosts was not significant. The transcript abundance data were normalized against expression in ' $\mathrm{Ca}$. L. asiaticus'-infected citrus.

\section{LasPrx5 and LasBCP are functional peroxiredoxins and mitigate oxidative stress in $L$. crescens.}

Lasprx 5 and Lasbcp were functionally characterized by heterologous expression in L. crescens BT-1, a culturable proxy for ' $\mathrm{Ca}$. L. asiaticus'. Both enzymes were individually cloned in the wide-host range (Rep Bordatella) shuttle vector pBBR1MCS-5 (Kovach et al. 1995) under control of a lacZ promoter and transformed into BT-1 cells. A protective role of ' $\mathrm{Ca}$. L. asiaticus' peroxiredoxins and $\mathrm{SC} 2$ peroxidase in alleviation of menadionegenerated intracellular ROS stress (Loor et al. 2010) was examined by staining BT-1 cells with the ROS-sensitive CellROX Deep Red reagent. Five-day-old BT-1 cells, transformed with the empty vector pBBR1MCS-5, pLF080 (lacZ::F489_gp15) (Jain et al. 2015), pSZ103 (lacZ::Lasprx5), or pSZ104 (lacZ::Lasbcp) were adjusted to an absorbance at $600 \mathrm{~nm}\left(\mathrm{Abs}_{600}\right)=1.0(200 \mu \mathrm{l})$ and were treated with $10 \mu \mathrm{M}$ menadione in the presence or absence of $50 \mu \mathrm{M}$ conoidin A, a covalent inhibitor that binds the active site Cys of peroxiredoxins (Nguyen et al. 2013). Menadione treatment resulted in a significant increase (15.6-fold) in fluorescence in BT-1/pBBR1MCS-5 cells, indicating greatly increased intracellular ROS stress (Fig. 2). By contrast, BT-1 cells expressing either the SC2 peroxidase or ' $C a$. L. asiaticus' peroxiredoxins displayed only a 5.3- to 6.0-fold increase in fluorescence. In the presence of the peroxiredoxin inhibitor conoidin $\mathrm{A}$, the menadione-induced increase in fluorescence was comparable in BT-1 cells carrying the empty vector, Lasprx 5, or Lasbcp. By contrast, conoidin A had no effect on BT-1 cells carrying the SC2 peroxidase, confirming the predicted function of the LasPrx 5 and LasBCP as peroxiredoxins and distinguishing these two enzymes from the SC2 peroxidase.

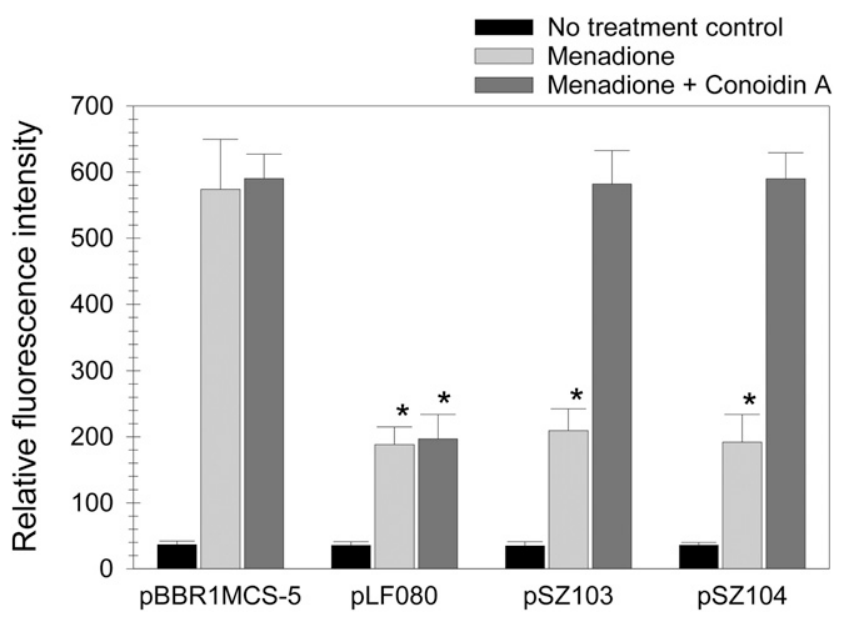

Fig. 2. 'Candidatus Liberibacter asiaticus' peroxiredoxins LasBCP and LasPrx 5 both alleviated oxidative stress in Liberibacter crescens BT-1. L. crescens BT- 1 cells $(200 \mu \mathrm{l}$, absorbance at $600 \mathrm{~nm}=1.0)$ were transformed with the empty vector pBBR1MCS-5, pLF080 (lacZ::F489_gp15), pSZ103 (lacZ::Lasprx5), or pSZ104 (lacZ::Lasbcp) and were treated with reactive oxygen species (ROS) generator menadione $(10 \mu \mathrm{M})$ and peroxiredoxin inhibitor conoidin A $(50 \mu \mathrm{M})$, as indicated. Intracellular ROS were detected by the florescent stain CellROX Deep Red (Ex/Em maxima 640/665 nm). The data presented are the means \pm standard error for three independent experiments with five replicates. Asterisks indicate significant differences between the means $(P<0.05)$.
LasPrx 5 and LasBCP increased

$L$. crescens cell viability in culture.

Five-day-old $L$. crescens BT-1 cells carrying the empty vector pBBR1MCS-5, pLF080, pSZ103, or pSZ104 (adjusted to $\mathrm{Abs}_{600}=$ $0.5)$ were challenged with $100 \mu \mathrm{M} \mathrm{H}_{2} \mathrm{O}_{2}$ or $50 \mu \mathrm{M}$ tert-butyl hydroperoxide $(t \mathrm{BOOH})$, an organic peroxide, for $30 \mathrm{~min}$ and were plated for enumerating the colony-forming units (Fig. 3). Expression of either of the ' $\mathrm{Ca}$. L. asiaticus' peroxiredoxins or the SC2 peroxidase in L. crescens BT-1 provided 1.3-fold higher cell viability in the absence of any exogenously provided oxidative stress, indicating that each of these enzymes increased ability to detoxify endogenously generated ROS as a result of aerobic respiration.

Even though $L$. crescens BT-1 carries two native peroxiredoxins (B488_RS02765 and B488_RS05115) and no known peroxidases, treatments of BT-1/pBBR1MCS-5 cells with the indicated amounts of $\mathrm{H}_{2} \mathrm{O}_{2}$ or $t \mathrm{BOOH}$ resulted in nearly complete loss of viability. BT-1/pSZ103 (Lasprx5) cells were 65fold more resistant to exogenous $\mathrm{H}_{2} \mathrm{O}_{2}$ as compared with BT-1 cells harboring the empty vector. LasPrx 5 conferred no detected protection against $t \mathrm{BOOH}$. BT-1/pSZ104 (Lasbcp) cells were 36and 214-fold more resistant to exogenous $\mathrm{H}_{2} \mathrm{O}_{2}$ and $t \mathrm{BOOH}$, respectively, than BT-1/pBBR1MCS-5. Heterologous expression of the previously characterized SC2 peroxidase in BT-1/pLF080 cells was also compared in these viability assays; $\mathrm{SC} 2$ peroxidase conferred 17-fold enhanced resistance to exogenous $\mathrm{H}_{2} \mathrm{O}_{2}$ as compared with BT-1/pBBR1MCS-5. These results provide evidence that ' $\mathrm{Ca}$. L. asiaticus' peroxiredoxins and the $\mathrm{SC} 2$ peroxidase play protective roles in redox homeostasis in L. crescens BT-1.

\section{Lasprx 5 and Lasbcp encode cytoplasmic} and extracellular peroxiredoxins, respectively.

' $C a$. L. asiaticus' peroxiredoxins were functionally corroborated by quantification of enzymatic degradation of $\mathrm{H}_{2} \mathrm{O}_{2}$ in spectrophotometric assays. L. crescens BT-1 cells transformed with either pSZ103 (Lasprx5) or pSZ104 (Lasbcp) displayed 1.5 and 2.3 -fold higher peroxidase activity in cell lysates $(4.3 \pm$ 0.1 and $6.6 \pm 1.1 \mathrm{mU}$, respectively) as compared with empty

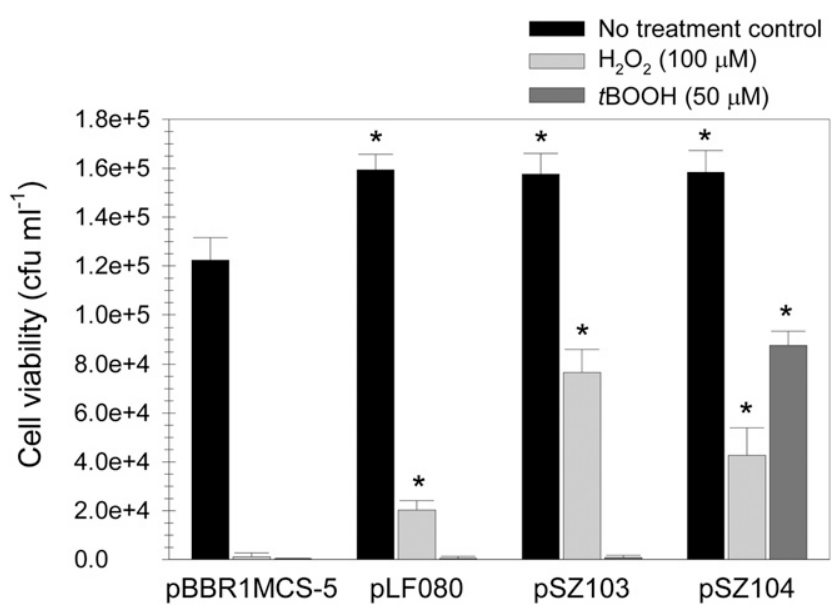

Fig. 3. 'Candidatus Liberibacter asiaticus' peroxiredoxins LasBCP and LasPrx 5 both enhanced viability of Liberibacter crescens BT-1 in culture. L. crescens BT- 1 cells $(1 \mathrm{ml}$, absorbance at $600 \mathrm{~nm}=0.5)$ were transformed with the empty vector pBBR1MCS-5, pLF080 (lacZ::F489_gp15), pSZ103 (lacZ::Lasprx5), or pSZ104 (lacZ::Lasbcp), were treated with $100 \mu \mathrm{M} \mathrm{H}_{2} \mathrm{O}_{2}$ or $50 \mu \mathrm{M}$ tert-butyl hydroperoxide $(t \mathrm{BOOH})$ for $30 \mathrm{~min}$, and were washed, serially diluted, and plated on selective BM7 media. The surviving bacterial colonies were scored after 3 weeks. The data presented are the means \pm standard error for three independent experiments with two replicates. Asterisks indicate significant differences between the means $(P<0.05)$. 
vector controls $(2.9 \pm 0.5 \mathrm{mU})$, assayed using 5-day-old BT-1 cell cultures adjusted to $\mathrm{Abs}_{600}=1.0$ (Fig. 4). BT-1/pLF080 cells expressing SC2 peroxidase also displayed significantly higher peroxidase activity (1.4-fold, $5.8 \pm 0.3 \mathrm{mU}$ ) as compared with BT-1/pSZ103 (Lasprx5) cells. Neither Lasprx5- nor Lasbcp-encoded protein products were predicted to carry signal peptides for extracellular bacterial secretion. However, nonclassical secretion potential was predicted by SecretomeP 2.0 (Bendtsen et al. 2005) for LasBCP (SecP score of 0.756256, cutoff 0.5). Consistent with the above predictions, BT-1/pSZ104 (Lasbcp) and BT-1/pLF080 (SC2 peroxidase) exhibited 10- and sixfold higher enzymatic activity in culture supernatants $(3.0 \pm$ 0.5 and $2.1 \pm 0.2 \mathrm{mU}$, respectively) as compared with culture supernatants of $L$. crescens BT- 1 carrying the empty vector $(0.35$ $\pm 0.06 \mathrm{mU})$. Enzyme activity in the supernatant of BT-1/pSZ103 (Lasprx5) cells was similar to that obtained from the empty vector control cells $(0.73 \pm 0.3 \mathrm{mU})$. A similar nonclassical secretion potential was predicted, using SecretomeP 2.0, for annotated $\mathrm{BCP}$ orthologs from other pathogenic Liberibacter species as well as for predicted BCP homologs from genera Agrobacterium, Rhizobium, Sinorhizobium, Xanthomonas, Pseudomonas, Erwinia, and Ralstonia.

\section{LasBCP suppressed transcriptional activation of $R$ boh in planta.}

Given that LasBCP is a secreted protein and its expression is unique to the citrus host, its function and significance in planta were investigated. Expression levels of $N b R b o h B$ in tobacco (Nicotiana benthamiana) were examined following Agrobacterium-mediated transient expression of the Lasbcp peroxiredoxin from the binary plasmid pAMB004 (CaMV35S:: Lasbcp) with or without coinfiltration of $\mathrm{H}_{2} \mathrm{O}_{2}$. In the absence of peroxide induction, no significant change in $\mathrm{NbRbohB}$ transcript abundance was observed between 2 and 6 days postinfiltration (dpi) of A. tumefaciens GV2260 carrying either pCAMBIA2301 (CaMV35S::uidA) or pAMB004 (Fig. 5A). Addition of (sublethal) $50 \mu \mathrm{M} \mathrm{H} \mathrm{H}_{2} \mathrm{O}_{2}$ to the suspension of GV2260/pCAMBIA2301 used for infiltration caused a reproducibly sharp increase in $N b R b o h B$ transcript abundance between 2 and 6 dpi (Fig. 5B). However, transient expression of

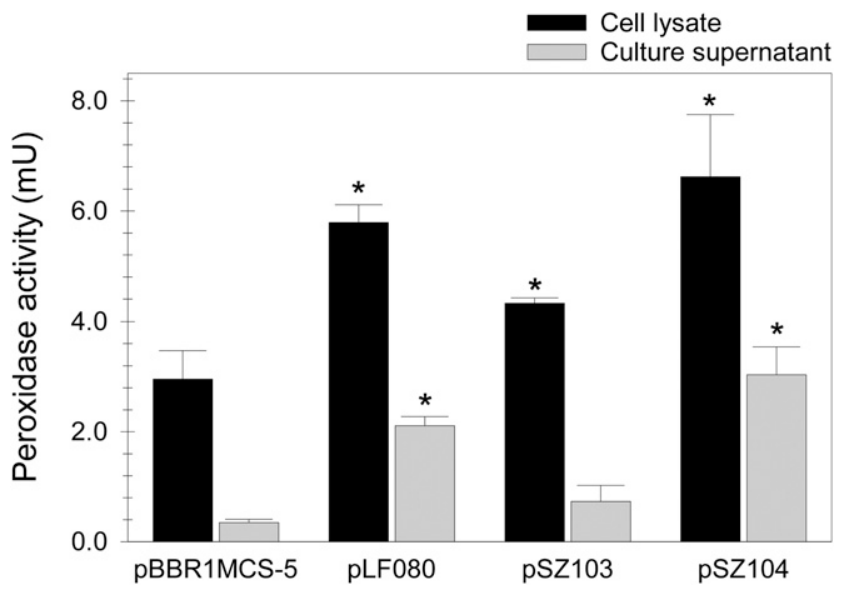

Fig. 4. Lasbcp encoded an extracellular peroxiredoxin in Liberibacter crescens BT-1. Peroxidase activity was quantified in $L$. crescens BT-1 cells transformed with the empty vector pBBR1MCS-5, pLF080 (lacZ::F489 gp15), pSZ103 (lacZ::Lasprx5), or pSZ104 (lacZ::Lasbcp). Five-day-old cultures were adjusted to an absorbance at $600 \mathrm{~nm}=1.0$, and the enzyme activity was measured in $0.5 \mathrm{ml}$ of cell lysates or $50 \mu \mathrm{l}$ of culture supernatants. The data presented are the means \pm standard error for three independent experiments with four replicates. Asterisks indicate significant differences between the means $(P<0.05)$.
Lasbcp in the presence of $\mathrm{H}_{2} \mathrm{O}_{2}$ significantly alleviated the sharp rise in $N b R b o h B$ transcriptional activity at 4 and 6 dpi $(P=0.000181$ and 0.000693 , respectively) (Fig. 5B). These results provided unambiguous evidence that LasBCP detoxified $\mathrm{H}_{2} \mathrm{O}_{2}$ in planta and thereby suppressed transcriptional activation of $N b R b o h B$.

\section{LasBCP suppressed ' $C a$. L. asiaticus' flagellin} (PAMP)-triggered immune responses in tobacco.

The effect of Lasbcp expression in tobacco on perception of the ' $C a$. L. asiaticus' flagellin peptide ( $f\left(g 22_{\text {Las }}\right)$ elicitor was examined by expression analyses of three PAMP perception and relay genes and response gene $N b R b o h B$ (Fig. 6). Infiltration of $40 \mu \mathrm{M}$ flg $22_{\text {Las }}$ in wild-type tobacco leaves resulted in a rapid increase in transcript abundance of flagellin sensing 2 (NbFLS2), BRI1-associated receptor kinase-1 (NbBAK1), and Botrytis-induced kinase-1 $(N b B I K l)$ within $1 \mathrm{~h}$ postinfiltration (hpi). A similar increase in flg22 $2_{\text {Las }}$-induced $N b F L S 2, N b B A K 1$, and $N b B I K 1$ transcriptional activity was also observed in tobacco leaves expressing Lasbcp at $1 \mathrm{hpi}$. However, in tobacco leaves transiently expressing Lasbcp, $N b R b o h B$ transcription was dramatically repressed $(P=0.000341)$ as compared with the levels elicited by the flg $22_{\text {Las }}$ peptide in wild-type tobacco leaves at 1 hpi.

The effect of Lasbcp expression in tobacco on callose deposition in response to perception of flg $22_{\text {Las }}$ was also examined (Fig. 7). Significant callose deposition was seen in tobacco

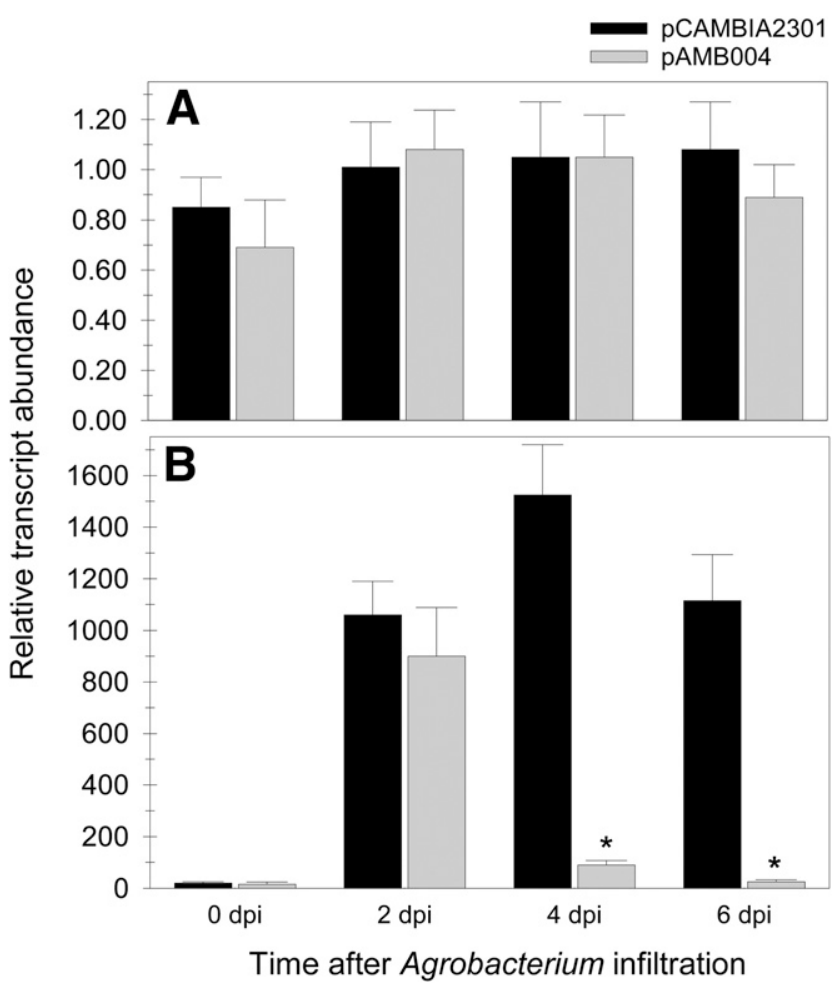

Fig. 5. Transient expression of Lasbcp in tobacco suppressed $\mathrm{H}_{2} \mathrm{O}_{2}$-induced transcriptional upregulation of defense-related gene $N b R b o h B$. A, Nicotiana benthamiana leaves were infiltrated with Agrobacterium tumefaciens GV2260 carrying the binary vectors pCAMBIA2301 (CaMV35S::uidA) and pAMB004 (CaMV35S::Lasbcp) without added $\mathrm{H}_{2} \mathrm{O}_{2}$ and $\mathbf{B}$, with $50 \mu \mathrm{M}$ $\mathrm{H}_{2} \mathrm{O}_{2}$ added. Infiltrated tissues from three individual leaves were excised at $0,2,4$, and 6 days postinfiltration (dpi) and were used for RNA extraction and quantitative reverse transcription-polymerase chain reaction analyses. $\mathrm{NbR}$ bohB expression was normalized against elongation factor $1 \alpha$ $(N b E F 1 \alpha)$ expression. The data presented are the means \pm standard error for three independent experiments with three replicates. Asterisks indicate significant differences between the treatment means $(P<0.05)$. 
leaf tissue responding to infiltration with $40 \mu \mathrm{M} \mathrm{flg} 22_{\text {Las }}$. Callose deposition was almost completely suppressed in tobacco leaves infiltrated with the same level of flg $22_{\text {Las }}$ by transient expression of Lasbcp in the same leaf region, while callose deposition was readily observed in the similarly treated tobacco leaves expressing $\beta$-glucuronidase (GUS) as the control. Taken together, these data provide unambiguous evidence that LasBCP did not interfere with flagellin signal perception (NbFLS2 and $N b B A K 1)$ or relay (NbBIK1) events, but rather, interrupted $\mathrm{H}_{2} \mathrm{O}_{2}$-mediated activation of $N b R b o h B$, leading to suppression of PAMP-triggered immune responses, including callose deposition.

\section{LasBCP alleviated oxidative damage to membrane lipids in planta.}

Tobacco leaf discs infiltrated with A. tumefaciens GV2260 (4 dpi) carrying the binary vectors pCAMBIA2301 (CaMV35S:: uidA), pAMB003 (CaMV35S::Lasprx5), and pAMB004 (CaMV35S::Lasbcp) were floated in Murashige Skoog (MS) medium (Murashige and Skoog 1962) containing 0, 25, and $50 \mathrm{mM} t \mathrm{BOOH}$, for 2 days, for quantification of total chlorophyll content as a visual indicator of $t \mathrm{BOOH}$-induced oxidative damage (Fig. 8A). These leaf disc senescence assays showed that $25-$ and $50-\mathrm{mM} t \mathrm{BOOH}$ treatments resulted in bleaching and significant loss of chlorophyll in GUS-expressing leaf discs (36 and 55\% loss, respectively) as compared with leaves expressing either LasPrx5 (30 and 32\% loss, respectively) or LasBCP (18 and 25\% loss, respectively). These results indicated a role of both peroxiredoxin genes in mitigating ROS-induced damage to the photosynthetic apparatus and chloroplast membranes.

Oxidative damage to free and membrane lipids was quantified by determining the total malondialdehyde (MDA) (an oxylipin) content in tobacco leaf discs floated in MS medium containing $t \mathrm{BOOH}$ (Fig. 8B). No significant differences were observed in MDA content in tobacco leaf discs floated in $0 \mathrm{mM}$ $t \mathrm{BOOH}$ and transiently expressing GUS, LasPrx5, or LasBCP $(0.88,0.93$, and 1.05 nmole MDA per microgram of fresh weight, respectively). The $25-$ or $50-\mathrm{mM} t \mathrm{BOOH}$ treatments

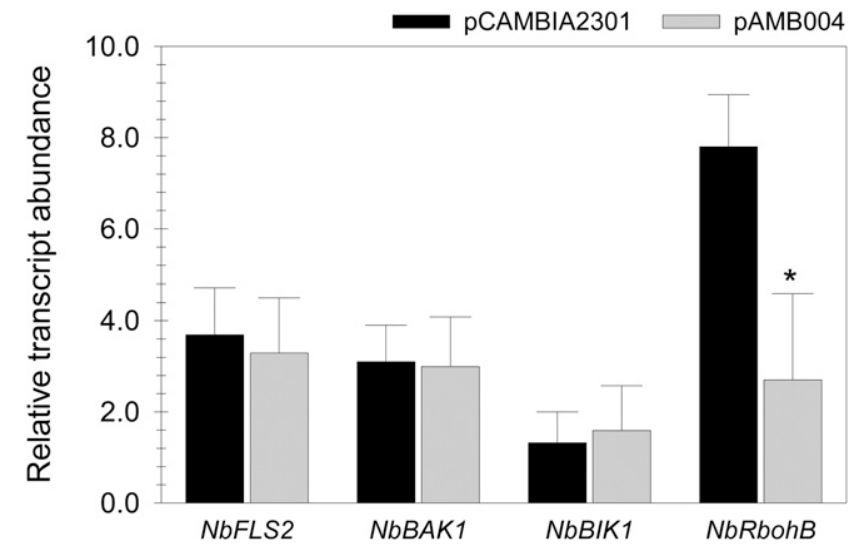

Fig. 6. Transient expression of Lasbcp in tobacco inhibited transcriptional upregulation of $N b R b o h B$ despite the perception of pathogen-associated molecular pattern signal flg22 Las. Nicotiana benthamiana leaves were infiltrated with Agrobacterium tumefaciens GV2260 carrying the binary vector pAMB004 (CaMV35S::Lasbcp). Four days later, the same leaves were infiltrated with $40 \mu \mathrm{M}$ flg $22_{\text {Las }}$ peptide. Expression of pattern-triggered immunity genes $N b F L S 2, N b B A K 1, N b B I K 1$, and $N b R b o h B 1 \mathrm{~h}$ postinfiltration (hpi) were normalized against elongation factor $1 \alpha$ $(N b E F 1 \alpha)$ expression and were calibrated against expression levels at $0 \mathrm{hpi}$. The data presented are the means \pm standard error for three independent experiments with three replicates. An asterisk indicates a significant difference between the treatment means $(P<0.05)$. resulted in a significant increase in MDA levels in tobacco leaf tissue expressing either GUS (17- and 20-fold, respectively) or LasPrx5 (11- and 16-fold, respectively), indicating no protective effect of LasPrx5 on lipid peroxidation. By contrast, LasBCP expression in tobacco leaf discs provided considerable protection against lipid peroxidation, resulting in a much lower 4.7- and 4.5-fold increase in MDA content when exposed to 25 or $50 \mathrm{mM} t \mathrm{BOOH}$, respectively. Taken together, these data demonstrate a protective role of secreted LasBCP to benefit ' $\mathrm{Ca}$. L. asiaticus' survival and colonization by alleviating ROSinduced lipid peroxidation in host cells, thereby alleviating both the direct effects of antimicrobial oxylipins and also the indirect effects of subsequent host cell death response.

\section{DISCUSSION}

Upon initial contact with hosts, pathogenic biotrophic bacteria must deal with host detection of PAMPs by actively suppressing the host-generated oxidative burst, typically by use of a large repertoire of often-redundant ROS defensive genes encoding multiple catalases, peroxidases (Klotz and Loewen 2003), and peroxiredoxins (Dubbs and Mongkolsuk 2007). However, all Liberibacter genomes are highly reduced, with an average size of approximately 1.2 Mb (Duan et al. 2009; Leonard et al. 2012; Lin et al. 2011; Wulff et al. 2014), and encode only two highly conserved Prx5-like and BCP-like predicted peroxiredoxins. 'Ca. L. asiaticus' strains with one or more prophages also encode an additional functional peroxidase (Jain et al. 2015; Zhang et al. 2011).

'Ca. L. asiaticus' peroxiredoxins Lasprx 5 and Lasbcp were functionally validated in the surrogate expression host $L$. crescens BT-1 (Leonard et al. 2012). L. crescens has its own pair of
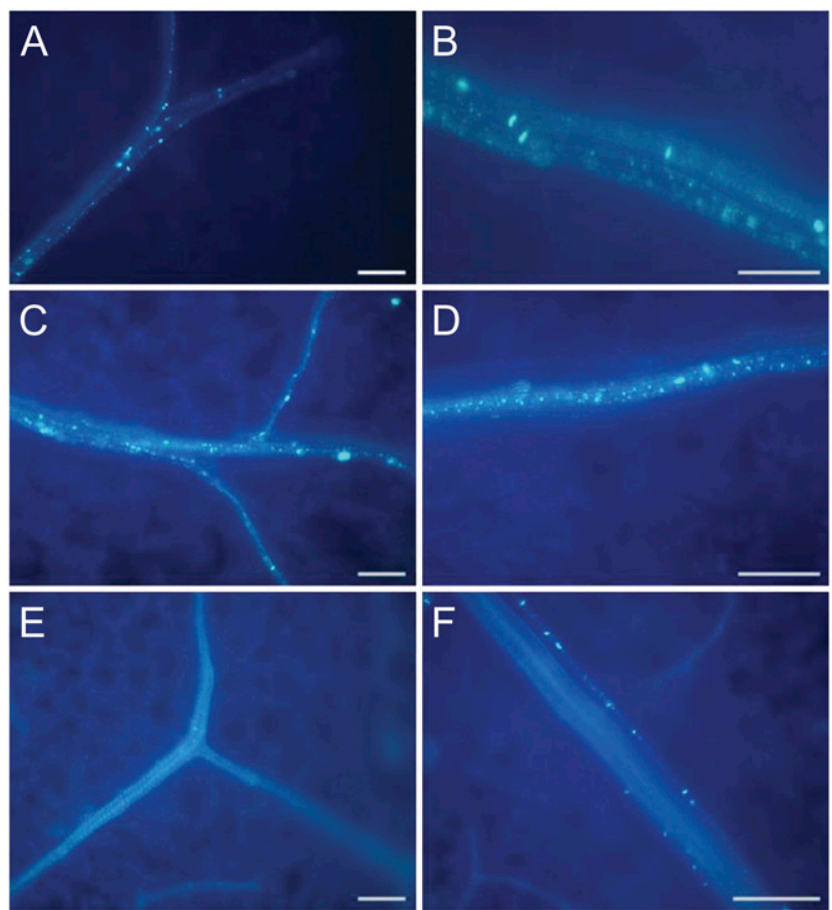

Fig. 7. Transient expression of Lasbcp in tobacco suppressed flg $22_{\text {Las }^{-}}$ induced callose deposition. Nicotiana benthamiana leaves were infiltrated with Agrobacterium tumefaciens GV2260 carrying the binary vector pCAMBIA2301 (CaMV35S::uidA) or pAMB004 (CaMV35S::Lasbcp). Four days later, the same leaves were infiltrated with $40 \mu \mathrm{M}$ flg $22_{\text {Las }}$ peptide. $\mathbf{A}$ and $\mathbf{B}$, Callose deposition was visualized by UV epifluorescence in wild-type leaves expressing either $\mathbf{C}$ and $\mathbf{D}, \beta$-glucuronidase or $\mathbf{E}$ and $\mathbf{F}$, LasBCP, $24 \mathrm{~h}$ after flg2 $22_{\text {Las }}$ infiltration. Magnification bars $=50 \mu \mathrm{m}$. 
(predicted secreted) peroxiredoxins, but these enzymes proved to be significantly less effective in mitigating oxidative stress than those from ' $\mathrm{Ca}$. L. asiaticus' (Figs. 2, 3, and 4). Since L. crescens is not known to be pathogenic, such efficacy may not be needed. Similar to the previously described ' $\mathrm{Ca}$. L. asiaticus' SC2 peroxidase (Jain et al. 2015), LasBCP was demonstrated to be a secreted, extracellular enzyme in L crescens, despite lacking a typical Sec secretion signal. The secreted SC2 peroxidase was also shown to confer significantly enhanced peroxidase activity to culture supernatants as compared with wild-type $L$. crescens cells (Fig. 4). The two enzymes presumably act together within plant host cells to suppress the ROS burst.

Putative BCP-like peroxiredoxins from many other pathogenic or symbiotic species from genera including Agrobacterium, Rhizobium, Sinorhizobium, Xanthomonas, Pseudomonas, Erwinia, and Ralstonia were also predicted by SecretomeP to be nonclassically secreted. However, to the best of our knowledge, this is the first report of evidence for a functional role of a bacterial BCP in modulation of host defense responses. In this work, LasBCP was functionally characterized as a pathogen-encoded extracellular peroxiredoxin that simultaneously compromised both RBOH-mediated systemic and oxylipin-mediated localized immunity in planta.

By contrast with secreted LasBCP, LasPrx5 was cytoplasmically retained (Fig. 4) but, nevertheless, conferred significant additional oxidative stress tolerance to $L$. crescens cells (Figs. 2 and 3). Also, in contrast with both the SC2 peroxidase (Jain et al. 2015) and Lasbcp, Lasprx5 transcript abundance was similar in citrus as well as in the psyllid (Fig. 1). Both cytoplasmic localization and similar transcript abundance in very different hosts suggest that LasPrx 5 has a general housekeeping function engaged in detoxification of endogenous ROS resulting from electron transport reactions (Cabiscol et al. 2000). LasPrx 5 may also provide protection against host-generated peroxides and increase bacterial fitness and viability in host cells. Exogenous $\mathrm{H}_{2} \mathrm{O}_{2}$ can readily permeate bacterial cell walls, causing oxidation of $\mathrm{Fe}^{2+}$ to $\mathrm{Fe}^{3+}$ via the Fenton reaction, resulting in $\mathrm{Zn}^{2+}$ mismetallation within the active sites of $\mathrm{Fe}$ dependent enzymes. This compromises Fe-dependent enzymatic activities, imposing metabolic bottlenecks and retarding cell growth and viability (Imlay 2014). Consistent with these observations, LasBCP and LasPrx 5 both enhanced growth of L. crescens in culture (Fig. 3) and would likely increase resistance to exogenous $\mathrm{H}_{2} \mathrm{O}_{2}$ in the host cell.

An essential role for catalase and peroxidase enzymes in virulence is well-established for both fungal and bacterial plant pathogens, including Ustilago maydis in maize (Molina and Kahmann 2007), Magnaporthe oryzae in rice (Samalova et al. 2014), Alternaria alternata (Lin et al. 2009), X. axonopodis pv. citri (Tondo et al. 2010), 'Ca. L. asiaticus' (Jain et al. 2015) in citrus, and $X$. campestris pv. campestris in Chinese radish (Jittawuttipoka et al. 2009). By contrast with either peroxidases or catalases, peroxiredoxins are generally cytoplasmic or compartmentalized but rarely extracellular (Wood et al. 2003). Furthermore, Cys-based peroxiredoxin activity is dependent upon the presence of thiol donors such as glutathione and thioredoxin (Hofmann et al. 2002) within the same cellular compartment. Peroxiredoxins have only been reported as virulence factors of plant-pathogenic nematodes ( $\mathrm{Li}$ et al. 2016) and of bacterial pathogens causing immunosuppression in animal hosts (Dons et al. 2014; Hillmann et al. 2016; Kaihami et al. 2014) but not, to our knowledge, of plant-pathogenic bacteria. To support phloem-limited intracellular growth of ' $\mathrm{Ca}$. L. asiaticus', LasBCP must be secreted into the phloem sap with an abundant supply of thiol donors (Carella et al. 2016). Peroxiredoxins are catalytically more efficient than catalases or peroxidases and are capable of degrading even sublethal micromolar levels of $\mathrm{H}_{2} \mathrm{O}_{2}$ (Seaver and Imlay 2001), thereby providing additional strategic advantage against the initial nonspecific low amplitude RBOH-mediated ROS burst (Baxter et al. 2014; Kadota et al. 2015).

Peroxide-induced activation of $\mathrm{RBOH}$ and generation of $\mathrm{H}_{2} \mathrm{O}_{2}$ via $\mathrm{RBOH}$ activity are imperative for systemic cell-tocell autopropagation of the immune signaling cascade in plants (Kadota et al. 2015; Miller et al. 2009). Phloem sap and sieve tube elements serve as checkpoints for the generation, amplification, propagation, and transport of $\mathrm{H}_{2} \mathrm{O}_{2}$ (Van Bel and Gaupels 2004). Lasbcp is expressed only in planta and not in psyllid hosts (Fig. 1). We hypothesize that extracellular LasBCP eliminates RBOH-generated $\mathrm{H}_{2} \mathrm{O}_{2}$ and is an essential virulence factor that enables ' $\mathrm{Ca}$. L. asiaticus' to evade early detection and clearing through innate immunity. ' $\mathrm{Ca}$. L. asiaticus' eventually builds up significant titers resulting in systemic colonization of citrus phloem over several months to years, resulting in surprisingly long disease-incubation periods (Chiyaka et al. 2012). An increase in pathogen load eventually leads to a $\mathrm{Zn}$ deficit in ' $\mathrm{Ca}$. L. asiaticus'-infected citrus cells (Nwugo et al. 2013; Vahling-Armstrong et al. 2012), aggravating oxidative damage primarily through diminished antioxidant activity, enhanced RBOH-mediated superoxide generation,

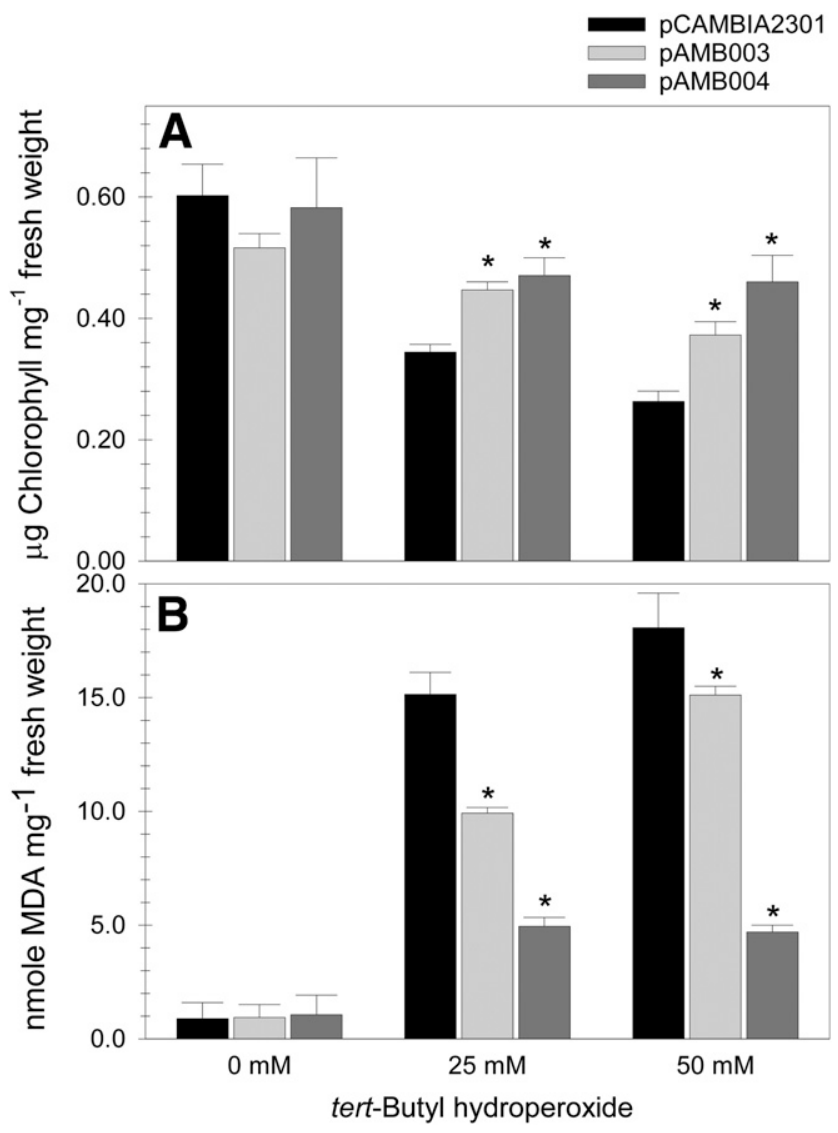

Fig. 8. LasBCP alleviated oxidative damage to membrane lipids in tobacco. A, Leaf discs excised from fully expanded Nicotiana benthamiana leaves transiently expressing pCAMBIA2301 (CaMV35S::uidA), pAMB003 (CaMV35S::Lasprx5), or pAMB004 (CaMV35S::Lasbcp) were floated for 2 days on liquid Murashige and Skoog medium containing 0, 25, or $50 \mathrm{mM}$ tert-butyl hydroperoxide and were harvested for quantification of total chlorophyll (Chl $a+b$ ) and $\mathbf{B}$, malondialdehyde (MDA content). The data presented are the means \pm standard error for three independent experiments with five replicates. Asterisks indicate significant differences between the treatment means $(P<0.05)$. 
and disruption of mitochondrial electron transport and photosynthetic $\mathrm{CO}_{2}$ fixation (Cakmak 2000; Eide 2011).

The 1-Cys LasBCP exhibited peroxidase activity against $\mathrm{H}_{2} \mathrm{O}_{2}$ and organic alkyl peroxides (Figs. 2, 3, and 4). LasBCP prevented activation of the $\mathrm{RBOH}$ signaling cascade (Figs. 5 and 6) and simultaneously suppressed oxidative deterioration of free and membrane-bound lipids in the host cell (Fig. 8), thereby preventing a host cell-death response. The entire suite of genes for flagellar biosynthesis is present in ' $\mathrm{Ca}$. L. asiaticus' (Duan et al. 2009), and the PAMP activity of ' $\mathrm{Ca}$. L. asiaticus' flagellin peptide flg22 2 Las has earlier been demonstrated in tobacco (Hao et al. 2014; Zou et al. 2012) as well as in citrus (Shi et al. 2017). Transient expression of Lasbcp in tobacco suppressed (exogenously supplied) $\mathrm{H}_{2} \mathrm{O}_{2}$-mediated transcriptional activation of $N b R b o h B$ (Fig. 5), suggesting a potentially crucial role for the ' $\mathrm{C} a$. L. asiaticus' secreted peroxiredoxin in attenuation of host defense responses. Moreover, transient Lasbcp expression did not interfere with the perception of flg2 $2_{\text {Las }}$ by FLS2, BAK1, or BIK1 but, instead, suppressed downstream $R b o h B$ autoactivation via an $\mathrm{H}_{2} \mathrm{O}_{2}$-mediated positive feedback loop (Fig. 6).

LasBCP, as a 1-Cys peroxiredoxin, is ideally suited as a virulence effector for sustained suppression of plant ROS defenses. 1-Cys peroxiredoxins are insensitive to redox regulation (reversible inactivation) through hyperoxidation of the peroxidatic Cys $\left(\mathrm{C}_{\mathrm{P}} / \mathrm{SO}_{2} \mathrm{H}\right)$ (Nelson et al. 2011). Oxidative inactivation of $\mathrm{C}_{\mathrm{P}} / \mathrm{SH}$ would promote localized buildup of $\mathrm{H}_{2} \mathrm{O}_{2}$ for participation in ROS signaling networks, a physiological function of 2-Cys peroxiredoxins that would clearly not be useful for intracellular pathogens such as ' $\mathrm{Ca}$. L. asiaticus'. Suppression of $\mathrm{RBOH}$ activity leads to the reduction of disease resistance accompanied by elimination of the oxidative burst (Yoshioka et al. 2003). Rboh transcriptional activity in citrus leaves was downregulated following ' $\mathrm{Ca}$. L. asiaticus' infection (Mafra et al. 2013). Furthermore, proteomic profiling of ' $\mathrm{Ca}$. L. asiaticus'-infected grapefruit leaves revealed decreased accumulation of several $\mathrm{H}_{2} \mathrm{O}_{2}$-scavenging as well as $\mathrm{H}_{2} \mathrm{O}_{2}$-responsive enzymes (Nwugo et al. 2013), providing additional evidence for active suppression of ROS signaling during ' $\mathrm{Ca}$. L. asiaticus' infection. A decline in proline concentration in ' $\mathrm{Ca}$. L. asiaticus'-infected citrus fruits was also attributed to a defenserelated $\mathrm{H}_{2} \mathrm{O}_{2}$ burst (Slisz et al. 2012).

In addition to providing $\mathrm{H}_{2} \mathrm{O}_{2}$ tolerance, LasBCP also provided a significant 214 -fold increase in viability of $L$. crescens BT-1 cells exposed to $t$ BOOH (Fig. 3). LasBCP prevented oxidative damage to plant membrane lipids and subsequent accumulation of oxylipins (Fig. 8). Oxylipins are formed in eukaryotic cells in response to a wide range of pathogens (García-Marcos et al. 2013; Sun et al. 2014). Both lipid peroxidation as well as lipase-based cleavage of membrane lipids and subsequent dioxygenation by lipoxygenases are stringently regulated within cells (Farmer and Mueller 2013). Lipoxygenase levels were significantly downregulated in ' $\mathrm{Ca}$. L. asiaticus'-infected citrus leaves (Fan et al. 2011; Nwugo et al. 2016). Furthermore, the increase in lipoxygenase substrates in citrus leaves caused by Diaphorina citri infestation was rapidly attenuated upon coinfection with ' $C a$. L. asiaticus', indicating active suppression of the oxylipin-mediated defense pathway (Killiny and Nehela 2017).

LasBCP is a uniquely suitable and, likely, critical effector for suppressing host defenses in support of an intracellular lifestyle, because it is secreted inside the plant cell cytoplasm and has a high affinity for organic peroxide radicals. Cytoplasmic LasPrx 5 and secreted LasBCP peroxiredoxins in ' $\mathrm{Ca}$. L. asiaticus' appeared to be important for both endogenous and host-generated ROS defense, respectively. LasBCP suppressed $\mathrm{H}_{2} \mathrm{O}_{2}$-mediated systemic defense signaling cascades in planta and, more importantly, also provided protection against peroxidative damage to free and membrane-bound lipids and subsequent accumulation of oxylipins. All pathogenic ' $\mathrm{Ca}$. Liberibacter sp.' are predicted to encode highly similar BCP-like enzymes, and all are predicted to be nonclassically secreted. Based on homology, we speculate that suppression of the accumulation of oxylipin, which exhibits antimicrobial activity and elicits hypersensitive host cell death, is critical for survival and phloem colonization not only for ' $\mathrm{Ca}$. L. asiaticus', but for all pathogenic Liberibacter species. These BCP-like enzymes are promising targets for chemical inactivation and development of therapeutic chemical controls of several severe plant diseases, including HLB.

\section{MATERIALS AND METHODS}

\section{Plant material and insect samples.}

' $C a$. L. asiaticus'-infected leaf samples were excised from the curated citrus (Citrus paradisi) plants maintained in a quarantine greenhouse at the University of Florida, Gainesville, Florida. ' $C a$. L. asiaticus'-infected mixed-sex adult psyllids (reared on sweet orange, $C$. sinensis; approximately $80 \%$ infection density) were provided by D. Hall, United States Department of Agriculture Agricultural Research Service (USDA-ARS).

\section{Bacterial strains and growth conditions.}

The relevant characteristics, sources, and references for the bacterial strains and plasmids used in this study are listed in Table 1. Escherichia coli and A. tumefaciens strains were grown in Luria-Bertani medium at 37 and $28^{\circ} \mathrm{C}$, respectively. L. crescens BT-1 was maintained on BM7 medium with gentle shaking at $150 \mathrm{rpm}$ at $28^{\circ} \mathrm{C}$ (Fleites et al. 2014; Jain et al. 2015). Antibiotics were used as needed at the following concentrations (in $\mu \mathrm{g} / \mathrm{ml}$ ): ampicillin 100, kanamycin 50, rifampicin 75 , and gentamycin 2 .

\section{Nucleic acid extraction and reverse transcription- quantitative polymerase chain reaction (RT-qPCR) from ' $\boldsymbol{C a}$. L. asiaticus'-infected psyllids and citrus.}

DNA was extracted from citrus leaf discs and whole psyllids using the DNeasy plant mini kit and a blood and tissue kit, respectively (Qiagen, Valencia, CA, U.S.A.). Presence of ' $\mathrm{Ca}$. L. asiaticus' in the infected citrus samples was confirmed using conventional and nested PCR primer sets OI1/OI2c (Jagoueix et al. 1996) and CG03F/CG05R (Zhou et al. 2007) (Table 2). For RNA, midribs of PCR-confirmed ' $\mathrm{Ca}$. L. asiaticus'-infected leaves and psyllids (10 insects pooled together) were ground with a cold mortar and pestle in lysis buffer RLT (provided with the Qiagen RNeasy plant mini kit). RNA was extracted following the manufacturer protocol, was diluted with nuclease-free water to $200 \mathrm{ng} \mu \mathrm{l}^{-1}$, and was cleaned with TURBO DNA-free (DNase) kit (Ambion, Austin, TX, U.S.A.). RT reactions were performed using $1 \mu \mathrm{g}$ of RNA template (iScript Advanced cDNA synthesis kit; Bio-Rad, Hercules, CA, U.S.A.). qRT-PCR analyses were performed using a CFX96 Touch Real-Time PCR detection system (Bio-Rad) as described (Fleites et al. 2014; Jain et al. 2015). All the primers used are summarized in Table 2. The transcript abundance data were normalized against expression in ' $C a$. L. asiaticus'-infected citrus. Data analyses and Student's $t$ tests $(P=0.05)$ were performed using the Bio-Rad CFX Manager software package 3.0.

\section{Construction of peroxiredoxin expression vectors and transformation in $L$. crescens BT-1.}

Lasprx 5 and Lasbcp coding sequences were PCR-amplified using high-fidelity AccuPrime Taq DNA polymerase (Invitrogen, Carlsbad, CA, U.S.A.) and were directionally cloned in pSC-A 
(StrataClone; Agilent Technologies, Santa Clara, CA, U.S.A.), using the primer pairs as described in Table 2. Following sequence confirmation, the cloned inserts were moved in widehost range shuttle vector pBBR1MCS-5 (Kovach et al. 1995) to yield the plasmids pSZ103 (lacZ::Lasprx5) and pSZ104 (lacZ:: Lasbcp). Electrocompetent $L$. crescens BT-1 cells were prepared and transformed with pSZ103 and pSZ104 as previously described (Fleites et al. 2014; Jain et al. 2015).

\section{Bioinformatic analyses for potential secretion signals for Lasprx 5 and Lasbcp.}

SignalP version 4.1 was used to identify potential secretion signals from protein sequences, using both default (discrimination
$[D]$ score cutoff of 0.45 ) and sensitive ( $D$ score cutoff of 0.34 ) values. Prediction of nonclassical secretion was performed using SecretomeP (Bendtsen et al. 2005).

\section{Measurement of ROS stress response and peroxide resistance assay.}

For measurement of ROS detoxification response, 5-day-old L. crescens cells, transformed with the empty vector pBBR1MCS5, pLF080 (Jain et al. 2015), pSZ103, or pSZ104 were adjusted to $\mathrm{Abs}_{600}=1.0$, and a $200-\mu \mathrm{l}$ cell suspension was treated with ROS generator menadione $(10 \mu \mathrm{M})$, either in the presence or absence of peroxiredoxin inhibitor conoidin A $(50 \mu \mathrm{M})$. CellROX Deep Red reagent (Molecular Probes, Eugene, OR,

Table 1. Bacterial strains and plasmids used in this study

\begin{tabular}{|c|c|c|}
\hline Strains or plasmids & Relevant characteristics $^{\mathbf{a}}$ & Reference or source \\
\hline Escherichia coli TOP10 & 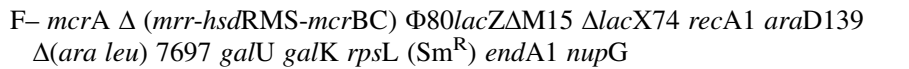 & Invitrogen \\
\hline Liberibacter crescens & Strain BT-1, originally isolated from mountain papaya & Leonard et al. 2012 \\
\hline Agrobacterium tumefaciens GV2260 & C58, Rif ${ }^{R}$, pGV2260 (pTiB6S3 3 T-DNA, $\mathrm{Cb}^{\mathrm{R}}$ ), octopine type & McBride and Summerfelt 1990 \\
\hline $\mathrm{pSC}-\mathrm{A}$ & $4.3 \mathrm{~kb}$; polymerase chain reaction cloning vector, $\mathrm{Ap}^{\mathrm{R}}, \mathrm{Kn}^{\mathrm{R}}$ & Agilent \\
\hline pBBR1MCS-5 & Rep Bordetella, lacZ $\mathrm{Z}^{+}, \mathrm{Gm}^{\mathrm{R}}$ & Kovach et al. 1995 \\
\hline pCAMBIA2301 & $\begin{array}{l}11.6 \mathrm{~kb} \text {; pPZP family binary vector, aadA (bacterial selection), nptII (plant } \\
\text { selection), enhanced } 35 \mathrm{~S} \text { promoter, castor bean catalase intron, uidA reporter } \\
\text { with } 6 \times \text { His-tag }\end{array}$ & Hajdukiewicz et al. 1994 \\
\hline pLF080 & pUFR071::F489_gp15::6×His-tag & Jain et al. 2015 \\
\hline pSZ103 & pBBR1MCS-5::Lasprx5 & This study \\
\hline pSZ104 & pBBR1MCS-5::Lasbcp & This study \\
\hline pAMB003 & $\begin{array}{l}\text { Lasprx } 5 \text { directionally cloned in pCAMBIA2301 replacing the uidA coding } \\
\text { sequence }\end{array}$ & This study \\
\hline pAMB004 & $\begin{array}{l}\text { Lasbcp directionally cloned in pCAMBIA2301 replacing the uidA coding } \\
\text { sequence }\end{array}$ & This study \\
\hline
\end{tabular}

${ }^{a} \mathrm{Sm}^{\mathrm{R}}, \mathrm{Rif}^{\mathrm{R}}, \mathrm{Cb}^{\mathrm{R}}, \mathrm{Ap}^{\mathrm{R}}, \mathrm{Kn}^{\mathrm{R}}$, and $\mathrm{Gm}^{\mathrm{R}}=$ streptomycin, rifampicin, carbenicillin, ampicillin, kanamycin, and gentamycin resistance.

Table 2. List of primers used in this study

\begin{tabular}{|c|c|c|}
\hline Primer & Sequence $\left(5^{\prime} \rightarrow 3^{\prime}\right)$ & Reference \\
\hline \multicolumn{3}{|l|}{ Las confirmation } \\
\hline OI1 & GCGCGTATGCAATACGAGCGGC & Jagoueix et al. 1996 \\
\hline $\mathrm{OI} 2 \mathrm{c}$ & GCCTCGCGACTTCGCAACCCAT & \\
\hline CG03F & RGGGAAAGATTTTATTGGAG & Zhou et al. 2007 \\
\hline CG05R & GAAAATAYCATCTCTGATATCGT & \\
\hline \multicolumn{3}{|c|}{ Quantitative reverse transcription-polymerase chain reaction } \\
\hline SZ30 (Lasprx5F) & GAGCTCCATAACGCCAAGAA & This study \\
\hline SZ31 (Lasprx5R) & TGATGGTTCGGGCGAATTTA & \\
\hline $\mathrm{SZ34}($ LasbcpF) & GTCAACTATCCTTATCGGCATCTC & This study \\
\hline $\mathrm{SZ35}$ (LasbcpR) & CTCATCGGCAAGCAGTGTAATA & \\
\hline LasprfAF & TGTCTGAATCGCCTTCTGTC & Fleites et al. 2014 \\
\hline LasprfAR & GATCACCGATGACAGTATGC & \\
\hline LasgyrBF & TTGAACAAGCTGTAATTTCTGG & Fleites et al. 2014 \\
\hline LasgyrBR & ATCTGTTTGCCAATTTAGAAGC & \\
\hline$N b F S L 2 \mathrm{~F}$ & TTCCTGTCTCTTTCGGGTAATG & This study \\
\hline$N b F S L 2 \mathrm{R}$ & TCCCTTATGCTTGAAGGAATGT & \\
\hline$N b B A K 1 \mathrm{~F}$ & GGTAGAGGTGGATTTGGTAAGG & This study \\
\hline$N b B A K 1 \mathrm{R}$ & CACCTTGAGTACGTTCCTCTTT & \\
\hline$N b B I K 1 \mathrm{~F}$ & CGGATAGTGTGTTGGGAGAAG & This study \\
\hline$N b B I K 1 \mathrm{R}$ & GCCCTCTTGGTTCAATCTCTTA & \\
\hline NbRbohBF & TTTCTCTGAGGTTTGCCAGCCACCACCTAA & Hao et al. 2014 \\
\hline NbRbohBR & GCCTTCATGTTGTTGACAATGTCTTTAACA & \\
\hline$N b E F 1 \alpha \mathrm{F}$ & GACCACTGAAGTTGGATCTGTTG & Hao et al. 2014 \\
\hline$N b E F 1 \alpha \mathrm{R}$ & TAGCACCAGTTGGGTCCTTCTT & \\
\hline \multicolumn{3}{|c|}{ Peroxiredoxin expression vectors } \\
\hline SZ28 (Lasprx5F) & GGATCCAGGAGTATGAAAATGATCCGATTTCAAATAC & This study \\
\hline SZ29 (Lasprx5R) & $\overline{A A G C T T}$ ctattttttactttctcgaataac & \\
\hline $\mathrm{SZ32}($ LasbcpF) & 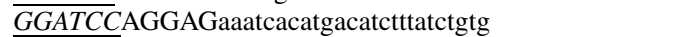 & This study \\
\hline $\mathrm{SZ33}$ (LasbcpR) & $\overline{A A G C T T T T A T T G T T T T A A G G A T T T T A C C A T C ~}$ & \\
\hline \multicolumn{3}{|c|}{ Peroxiredoxin binary vectors } \\
\hline AMB36 (LasbcpF) & GCTGACGACTACCAGTCATGACATCTTTATCTGTG & This study \\
\hline AMB37 (LasbcpR) & GCGACGCACGTGTTATTGTTTTAAGGATTTTACC & \\
\hline AMB39 (Lasprx5F) & GCTGAC $\overline{G A C T A C C A G T C A T G A T C C G A T T T C A A A T A C}$ & This study \\
\hline AMB40 (Lasprx5R) & GCGACGCACGTGCTATTTTTTACTTTCTCG & \\
\hline
\end{tabular}


U.S.A.) was added at a final concentration of $5 \mu \mathrm{M}$, and the cells were incubated for $30 \mathrm{~min}$ at $28^{\circ} \mathrm{C}$. Subsequently, the cells were washed three times with cold phosphate-buffered saline and the fluorescence was measured (Ex/Em maxima $640 / 665 \mathrm{~nm}$ ). For examining the peroxide tolerance, 5-day-old L. crescens cells transformed with pLF080, pSZ104, and pSZ105 were harvested and resuspended in BM7 medium, to a density of $\mathrm{Abs}_{600}=0.5$ and $1 \mathrm{ml}$ of resuspended bacteria were treated with $100 \mu \mathrm{M} \mathrm{H}_{2} \mathrm{O}_{2}$ or $50 \mu \mathrm{M} t \mathrm{BOOH}$ for $30 \mathrm{~min}$, were washed twice in BM7 medium, were serially diluted, and were plated on selective BM7 media. The surviving bacterial colonies were scored after 3 weeks.

\section{Peroxidase activity determination.}

Enzymatic peroxidase activity was measured using the Amplex Red hydrogen peroxide/peroxidase assay kit (Invitrogen). Aliquots of 5-day-old L. crescens cultures $(1.0 \mathrm{ml}$, adjusted to $\mathrm{Abs}_{600}=1.0$ ) were harvested by centrifugation and were resuspended in $50 \mu \mathrm{l}$ of $0.25 \mathrm{M}$ sodium phosphate buffer (pH 7.4). An equal volume of $100 \mu \mathrm{M}$ AmplexRed reagent (10acetyl-3,7-dihydroxyphenoxazine) and $2 \mathrm{mM} \mathrm{H}_{2} \mathrm{O}_{2}$ was added to the bacterial suspension and was incubated for $30 \mathrm{~min}$ in the dark. The development of red-chromogenic oxidation product resorufin was measured at $560 \mathrm{~nm}$. The enzyme activity was normalized against a standard curve obtained for horseradish peroxidase; $1 \mathrm{U}$ enzyme activity is defined as the amount of enzyme that will form $1.0 \mathrm{mg}$ of purpurogallin from pyrogallol in $20 \mathrm{~s}$ at $\mathrm{pH} 6.0$ and $20^{\circ} \mathrm{C}$.

\section{Agrobacterium-mediated transient expression \\ of ' $\mathrm{Ca}$. L. asiaticus' peroxiredoxin genes in tobacco.}

Lasprx 5 and Lasbcp were PCR-amplified from ' $C a$. L. asiaticus'-infected psyllid DNA and were cloned in pCR2.1TOPO (Invitrogen), using the primer pairs described in Table 2. Following sequence verification, Lasprx 5 and Lasbcp were directionally subcloned into pCAMBIA2301 (CaMV35S::uidA) between $A d h \mathrm{I}$ and $P m l \mathrm{I}$ sites, replacing uidA (Hajdukiewicz et al. 1994). The resulting plasmids pAMB003 (CaMV35S:: Lasprx5) and pAMB004 (CaMV35S::Lasbcp) were mobilized into A. tumefaciens GV2260 via electroporation. Agrobacteriummediated transient expression assays in tobacco (N. benthamiana) were performed as described previously (Hao et al. 2014). Synthetic flg22 Las peptide (DRVSSGLRVSDAADNAAYWSIA) (Life Tein Company, South Plainfield, NJ, U.S.A.) was diluted in water to a final concentration of $40 \mu \mathrm{M}$ and was infiltrated into tobacco leaves with a 1-ml needleless syringe. The infiltrated leaf tissues were sampled for RNA extraction, cDNA synthesis, and RT-qPCR analysis as described (Jain et al. 2015).

\section{Callose deposition assay.}

Callose deposition in flg22 $2_{\text {Las }}$-infiltrated leaves was detected with aniline staining as described previously (Hao et al. 2014). Briefly, the tissue was cleared and dehydrated in $100 \%$ ethanol. Cleared leaves were washed with distilled water and were then stained overnight at room temperature in $0.01 \%$ aniline blue in $67 \mathrm{mM} \mathrm{K}_{2} \mathrm{HPO}_{4}$ (pH 12). Stained material was mounted in $50 \%$ glycerol and was observed under ultraviolet epifluorescence (LSM5 Pascal confocal laser scanning microscope; Carl Zeiss Microscopy LLC, Thornwood, NY, U.S.A.).

\section{Quantification of oxidative membrane injury.}

Leaf discs from fully expanded tobacco leaves transiently expressing pCAMBIA2301, pAMB003, or pAMB004 were floated on liquid MS basal medium (Murashige and Skoog 1962) containing 0 to $50 \mathrm{mM} t \mathrm{BOOH}$. Total chlorophyll content in the leaf discs was estimated after 2 days, according to the procedure of Arnon (1949). The lipid peroxidation reaction end product, i.e., MDA, was measured using the MDA assay kit (Sigma-Aldrich, St. Louis). MDA reacts with thiobarbituric acid to form a fluorimetric product (Ex/Em maxima 532/553 nm).

\section{Statistical analyses.}

All data were analyzed using SAS for Windows, version 9.2 (SAS Institute Inc, Cary, NC, U.S.A.) and Student $t$ tests were performed to separate treatment means. A probability of $5 \%$ was used to determine statistically significant differences.

\section{ACKNOWLEDGMENTS}

We thank P. Rayside for excellent technical assistance, J. Rollins, Plant Pathology, University of Florida, Gainesville, FL, U.S.A. for help with florescent microscopy, and D. Hall, USDA-ARS, Fort Pierce, FL, U.S.A. for providing ' $\mathrm{Ca}$. L. asiaticus'-infected psyllids.

\section{LITERATURE CITED}

Arnon, D. I. 1949. Copper enzymes in isolated chloroplasts. Polyphenoloxidase in Beta vulgaris. Plant Physiol. 24:1-15.

Baxter, A., Mittler, R., and Suzuki, N. 2014. ROS as key players in plant stress signalling. J. Exp. Bot. 65:1229-1240.

Bendtsen, J. D., Kiemer, L., Fausbøll, A., and Brunak, S. 2005. Nonclassical protein secretion in bacteria. BMC Microbiol. 5:58.

Boutrot, F., and Zipfel, C. 2017. Function, discovery, and exploitation of plant pattern recognition receptors for broad-spectrum disease resistance. Annu. Rev. Phytopathol. 55:257-286.

Cabiscol, E., Tamarit, J., and Ros, J. 2000. Oxidative stress in bacteria and protein damage by reactive oxygen species. Int. Microbiol. 3:3-8.

Cakmak, I. 2000. Tansley review no. 111. Possible roles of zinc in protecting plant cells from damage by reactive oxygen species. New Phytol. 146:185-205

Carella, P., Merl-Pham, J., Wilson, D. C., Dey, S., Hauck, S. M., Vlot, C., and Cameron, R. K. 2016. Comparative proteomics analysis of Arabidopsis phloem exudates collected during the induction of systemic acquired resistance. Plant Physiol. 171:1495-1510.

Chiyaka, C., Singer, B. H., Halbert, S. E., Morris, J. G., Jr., and van Bruggen, A. H. C. 2012. Modeling huanglongbing transmission within a citrus tree. Proc. Natl. Acad. Sci. U.S.A. 109:12213-12218.

Choi, H. W., and Klessig, D. F. 2016. DAMPs, MAMPs, and NAMPs in plant innate immunity. BMC Plant Biol. 16:232.

Dons, L. E., Mosa, A., Rottenberg, M. E., Rosenkrantz, J. T., Kristensson, K., and Olsen, J. E. 2014. Role of the Listeria monocytogenes 2-Cys peroxiredoxin homologue in protection against oxidative and nitrosative stress and in virulence. Pathog. Dis. 70:70-74.

Duan, Y., Zhou, L., Hall, D. G., Li, W., Doddapaneni, H., Lin, H., Liu, L., Vahling, C. M., Gabriel, D. W., Williams, K. P., Dickerman, A., Sun, Y., and Gottwald, T. 2009. Complete genome sequence of citrus huanglongbing bacterium, 'Candidatus Liberibacter asiaticus' obtained through metagenomics. Mol. Plant-Microbe Interact. 22:1011-1020.

Dubbs, J. M., and Mongkolsuk, S. 2007. Peroxiredoxins in bacterial antioxidant defense. Pages 143-193 in: Peroxiredoxin Systems. L. Flohé and J. R. Harris, eds. Springer Netherlands, Dordrecht, The Netherlands.

Eide, D. J. 2011. The oxidative stress of zinc deficiency. Metallomics 3: 1124-1129.

Evrard, C., Capron, A., Marchand, C., Clippe, A., Wattiez, R., Soumillion, P., Knoops, B., and Declercq, J. P. 2004. Crystal structure of a dimeric oxidized form of human peroxiredoxin 5. J. Mol. Biol. 337:1079-1090.

Fan, J., Chen, C., Yu, Q., Brlansky, R. H., Li, Z. G., and Gmitter, F. G., Jr 2011. Comparative iTRAQ proteome and transcriptome analyses of sweet orange infected by "Candidatus Liberibacter asiaticus". Physiol. Plant. 143:235-245.

Farmer, E. E., and Mueller, M. J. 2013. ROS-mediated lipid peroxidation and RES-activated signaling. Annu. Rev. Plant Biol. 64:429-450.

Fleites, L. A., Jain, M., Zhang, S., and Gabriel, D. W. 2014. "Candidatus Liberibacter asiaticus" prophage late genes may limit host range and culturability. Appl. Environ. Microbiol. 80:6023-6030.

García-Marcos, A., Pacheco, R., Manzano, A., Aguilar, E., and Tenllado, F. 2013. Oxylipin biosynthesis genes positively regulate programmed cell death during compatible infections with the synergistic pair Potato virus $X$-Potato virus $Y$ and Tomato spotted wilt virus. J. Virol. 87: 5769-5783.

Ghanim, M., Achor, D., Ghosh, S., Kontsedalov, S., Lebedev, G., and Levy, A. 2017. 'Candidatus Liberibacter asiaticus' accumulates inside 
endoplasmic reticulum associated vacuoles in the gut cells of Diaphorina citri. Sci. Rep. 7:16945.

Grafton-Cardwell, E. E., Stelinski, L. L., and Stansly, P. A. 2013. Biology and management of Asian citrus psyllid, vector of the huanglongbing pathogens. Annu. Rev. Entomol. 58:413-432.

Grant, J. J., and Loake, G. J. 2000. Role of reactive oxygen intermediates and cognate redox signaling in disease resistance. Plant Physiol. 124: 21-29.

Hajdukiewicz, P., Svab, Z., and Maliga, P. 1994. The small, versatile pPZP family of Agrobacterium binary vectors for plant transformation. Plant Mol. Biol. 25:989-994.

Hao, G., Pitino, M., Ding, F., Lin, H., Stover, E., and Duan, Y. 2014. Induction of innate immune responses by flagellin from the intracellular bacterium, 'Candidatus Liberibacter solanacearum'. BMC Plant Biol. $14: 211$.

Hillmann, F., Bagramyan, K., Straßburger, M., Heinekamp, T., Hong, T. B., Bzymek, K. P., Williams, J. C., Brakhage, A. A., and Kalkum, M. 2016. The crystal structure of peroxiredoxin Asp f3 provides mechanistic insight into oxidative stress resistance and virulence of Aspergillus fumigatus. Sci. Rep. 6:33396.

Hofmann, B., Hecht, H. J., and Flohé, L. 2002. Peroxiredoxins. Biol. Chem. 383:347-364.

Imlay, J. A. 2014. The mismetallation of enzymes during oxidative stress. J. Biol. Chem. 289:28121-28128.

Jagoueix, S., Bové, J. M., and Garnier, M. 1996. PCR detection of the two 'Candidatus Liberobacter species associated with greening disease of citrus. Mol. Cell. Probes 10:43-50.

Jain, M., Fleites, L. A., and Gabriel, D. W. 2015. Prophage-encoded peroxidase in 'Candidatus Liberibacter asiaticus' is a secreted effector that suppresses plant defenses. Mol. Plant-Microbe Interact. 28: 1330-1337.

Jittawuttipoka, T., Buranajitpakorn, S., Vattanaviboon, P., and Mongkolsuk, S. 2009. The catalase-peroxidase KatG is required for virulence of Xanthomonas campestris pv. campestris in a host plant by providing protection against low levels of $\mathrm{H}_{2} \mathrm{O}_{2}$. J. Bacteriol. 191:7372-7377.

Kadota, Y., Shirasu, K., and Zipfel, C. 2015. Regulation of the NADPH oxidase RBOHD during plant immunity. Plant Cell Physiol. 56: 1472-1480.

Kaihami, G. H., Almeida, J. R., Santos, S. S., Netto, L. E. S., Almeida, S. R., and Baldini, R. L. 2014. Involvement of a 1-Cys peroxiredoxin in bacterial virulence. PLoS Pathog. 10:e1004442.

Katoh, H., Miyata, S., Inoue, H., and Iwanami, T. 2014. Unique features of a Japanese 'Candidatus Liberibacter asiaticus' strain revealed by whole genome sequencing. PLoS One 9:e106109.

Killiny, N., and Nehela, Y. 2017. Metabolomic response to huanglongbing: Role of carboxylic compounds in Citrus sinensis response to 'Candidatus Liberibacter asiaticus' and its vector, Diaphorina citri. Mol. Plant-Microbe Interact. 30:666-678.

Klotz, M. G., and Loewen, P. C. 2003. The molecular evolution of catalatic hydroperoxidases: Evidence for multiple lateral transfer of genes between prokaryota and from bacteria into eukaryota. Mol. Biol. Evol. 20:1098-1112.

Kovach, M. E., Elzer, P. H., Hill, D. S., Robertson, G. T., Farris, M. A., Roop, R. M., 2nd, and Peterson, K. M. 1995. Four new derivatives of the broad-host-range cloning vector pBBR1MCS, carrying different antibiotic-resistance cassettes. Gene 166:175-176.

Leonard, M. T., Fagen, J. R., Davis-Richardson, A. G., Davis, M. J., and Triplett, E. W. 2012. Complete genome sequence of Liberibacter crescens BT-1. Stand. Genomic Sci. 7:271-283.

Li, Z., Zhang, Q., and Zhou, X. 2016. A 2-Cys peroxiredoxin in response to oxidative stress in the pine wood nematode, Bursaphelenchus xylophilus. Sci. Rep. 6:27438.

Lin, C.-H., Yang, S. L., and Chung, K.-R. 2009. The YAP1 homologmediated oxidative stress tolerance is crucial for pathogenicity of the necrotrophic fungus Alternaria alternata in citrus. Mol. Plant-Microbe Interact. 22:942-952

Lin, H., Lou, B., Glynn, J. M., Doddapaneni, H., Civerolo, E. L., Chen, C., Duan, Y., Zhou, L., and Vahling, C. M. 2011. The complete genome sequence of 'Candidatus Liberibacter solanacearum', the bacterium associated with potato zebra chip disease. PLoS One 6:e19135

Loor, G., Kondapalli, J., Schriewer, J. M., Chandel, N. S., Vanden Hoek, T. L., and Schumacker, P. T. 2010. Menadione triggers cell death through ROS-dependent mechanisms involving PARP activation without requiring apoptosis. Free Radic. Biol. Med. 49:1925-1936.

Mafra, V., Martins, P. K., Francisco, C. S., Ribeiro-Alves, M., FreitasAstúa, J., and Machado, M. A. 2013. Candidatus Liberibacter americanus induces significant reprogramming of the transcriptome of the susceptible citrus genotype. BMC Genomics 14:247.
Mann, M., Fattah-Hosseini, S., Ammar, E. D., Stange, R., Warrick, E., Sturgeon, K., Shatters, R., and Heck, M. 2018. Diaphorina citri nymphs are resistant to morphological changes induced by "Candidatus Liberibacter asiaticus" in midgut epithelial cells. Infect. Immun. 86:e00889-17.

McBride, K. E., and Summerfelt, K. R. 1990. Improved binary vectors for Agrobacterium-mediated plant transformation. Plant Mol. Biol. 14: 269-276.

Miller, G., Schlauch, K., Tam, R., Cortes, D., Torres, M. A., Shulaev, V., Dangl, J. L., and Mittler, R. 2009. The plant NADPH oxidase RBOHD mediates rapid systemic signaling in response to diverse stimuli. Sci. Signal. 2:ra45.

Molina, L., and Kahmann, R. 2007. An Ustilago maydis gene involved in $\mathrm{H}_{2} \mathrm{O}_{2}$ detoxification is required for virulence. Plant Cell 19:2293-2309.

Murashige, T., and Skoog, F. 1962. A revised medium for rapid growth and bio assays with tobacco tissue cultures. Physiol. Plant. 15:473-497.

Nelson, K. J., Knutson, S. T., Soito, L., Klomsiri, C., Poole, L. B., and Fetrow, J. S. 2011. Analysis of the peroxiredoxin family: Using activesite structure and sequence information for global classification and residue analysis. Proteins 79:947-964.

Nguyen, J. B., Pool, C. D., Wong, C. Y., Treger, R. S., Williams, D. L., Cappello, M., Lea, W. A., Simeonov, A., Vermeire, J. J., and Modis, Y 2013. Peroxiredoxin-1 from the human hookworm Ancylostoma ceylanicum forms a stable oxidized decamer and is covalently inhibited by conoidin A. Chem. Biol. 20:991-1001.

Nwugo, C. C., Doud, M. S., Duan, Y. P., and Lin, H. 2016. Proteomics analysis reveals novel host molecular mechanisms associated with thermotherapy of ' $\mathrm{Ca}$. Liberibacter asiaticus'-infected citrus plants. BMC Plant Biol. 16:253.

Nwugo, C. C., Duan, Y., and Lin, H. 2013. Study on citrus response to huanglongbing highlights a down-regulation of defense-related proteins in lemon plants upon ' $\mathrm{Ca}$. Liberibacter asiaticus' infection. PLoS One 8: e67442.

Pitino, M., Armstrong, C. M., Cano, L. M., and Duan, Y. 2016. Transient expression of Candidatus Liberibacter asiaticus effector induces cell death in Nicotiana benthamiana. Front. Plant Sci. 7:982.

Prost, I., Dhondt, S., Rothe, G., Vicente, J., Rodriguez, M. J., Kift, N., Carbonne, F., Griffiths, G., Esquerré-Tugayé, M. T., Rosahl, S., Castresana, C., Hamberg, M., and Fournier, J. 2005. Evaluation of the antimicrobial activities of plant oxylipins supports their involvement in defense against pathogens. Plant Physiol. 139:1902-1913.

Samalova, M., Meyer, A. J., Gurr, S. J., and Fricker, M. D. 2014. Robust anti-oxidant defences in the rice blast fungus Magnaporthe oryzae confer tolerance to the host oxidative burst. New Phytol. 201:556-573.

Schieber, M., and Chandel, N. S. 2014. ROS function in redox signaling and oxidative stress. Curr. Biol. 24:R453-R462.

Seaver, L. C., and Imlay, J. A. 2001. Alkyl hydroperoxide reductase is the primary scavenger of endogenous hydrogen peroxide in Escherichia coli. J. Bacteriol. 183:7173-7181.

Shi, Q., Febres, V. J., Zhang, S., Yu, F., McCollum, G., Hall, D. G., Moore, G. A., and Stover, E. 2017. Identification of gene candidates associated with huanglongbing tolerance, using 'Candidatus Liberibacter asiaticus' flagellin 22 as a proxy to challenge citrus. Mol. Plant-Microbe Interact. 31:200-211.

Singh, A., Kumar, N., Tomar, P. P. S., Bhose, S., Ghosh, D. K., Roy, P., and Sharma, A. K. 2017. Characterization of a bacterioferritin comigratory protein family 1-Cys peroxiredoxin from Candidatus Liberibacter asiaticus. Protoplasma 254:1675-1691.

Slisz, A. M., Breksa, A. P., 3rd, Mishchuk, D. O., McCollum, G., and Slupsky, C. M. 2012. Metabolomic analysis of citrus infection by 'Candidatus Liberibacter' reveals insight into pathogenicity. J. Proteome Res. 11:4223-4230.

Sun, L., Zhu, L., Xu, L., Yuan, D., Min, L., and Zhang, X. 2014. Cotton cytochrome P450 CYP82D regulates systemic cell death by modulating the octadecanoid pathway. Nat. Commun. 5:5372.

Tondo, M. L., Petrocelli, S., Ottado, J., and Orellano, E. G. 2010. The monofunctional catalase KatE of Xanthomonas axonopodis pv. citri is required for full virulence in citrus plants. PLoS One 5:e10803.

Vahling-Armstrong, C. M., Zhou, H., Benyon, L., Morgan, J. K., and Duan, Y. 2012. Two plant bacteria, S. meliloti and $\mathrm{Ca}$. Liberibacter asiaticus, share functional $z n u A B C$ homologues that encode for a high affinity zinc uptake system. PLoS One 7:e37340.

Van Bel, A. J. E., and Gaupels, F. 2004. Pathogen-induced resistance and alarm signals in the phloem. Mol. Plant Pathol. 5:495-504.

Wood, Z. A., Schröder, E., Robin Harris, J., and Poole, L. B. 2003. Structure, mechanism and regulation of peroxiredoxins. Trends Biochem. Sci. 28:32-40.

Wu, F., Kumagai, L., Liang, G., Deng, X., Zheng, Z., Keremane, M., and Chen, J. 2015. Draft genome sequence of "Candidatus Liberibacter 
asiaticus" from a citrus tree in San Gabriel, California. Genome Announc. 3:e01508-e01515.

Wulff, N. A., Zhang, S., Setubal, J. C., Almeida, N. F., Martins, E. C., Harakava, R., Kumar, D., Rangel, L. T., Foissac, X., Bové, J. M., and Gabriel, D. W. 2014. The complete genome sequence of 'Candidatus Liberibacter americanus', associated with citrus huanglongbing. Mol. Plant-Microbe Interact. 27:163-176.

Yoshioka, H., Numata, N., Nakajima, K., Katou, S., Kawakita, K. Rowland, O., Jones, J. D., and Doke, N. 2003. Nicotiana benthamiana gp9lphox homologs NbrbohA and NbrbohB participate in $\mathrm{H}_{2} \mathrm{O}_{2}$ accumulation and resistance to Phytophthora infestans. Plant Cell 15: 706-718.

Zhang, S., Flores-Cruz, Z., Zhou, L., Kang, B.-H., Fleites, L. A., Gooch, M. D., Wulff, N. A., Davis, M. J., Duan, Y.-P., and Gabriel, D. W. 2011. ' $\mathrm{Ca}$. Liberibacter asiaticus' carries an excision plasmid prophage and a chromosomally integrated prophage that becomes lytic in plant infections. Mol. Plant-Microbe Interact. 24:458-468.
Zheng, Z., Sun, X., Deng, X., and Chen, J. 2015. Whole-genome sequence of "Candidatus Liberibacter asiaticus" from a huanglongbing-affected citrus tree in central Florida. Genome Announc. 3:e00169-15.

Zhou, L. J., Gabriel, D. W., Duan, Y. P., Halbert, S. E., and Dixon, W. N. 2007. First report of dodder transmission of huanglongbing from naturally infected Murraya paniculata to citrus. Plant Dis. 91: 227.

Zou, H., Gowda, S., Zhou, L., Hajeri, S., Chen, G., and Duan, Y. 2012. The destructive citrus pathogen, 'Candidatus Liberibacter asiaticus' encodes a functional flagellin characteristic of a pathogen-associated molecular pattern. PLoS One 7:e46447.

\section{AUTHOR-RECOMMENDED INTERNET RESOURCES}

SecretomeP version 2.0: http://www.cbs.dtu.dk/services/SecretomeP SignalP version 4.1: http://www.cbs.dtu.dk/services/SignalP 